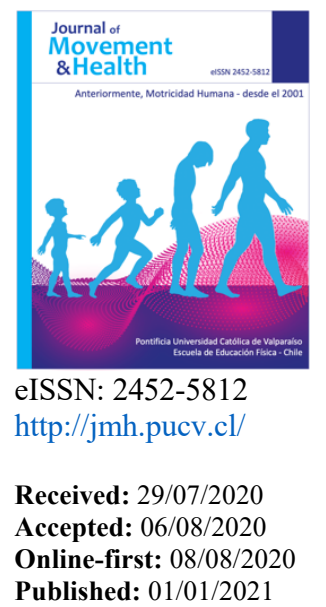

Published: 01/01/2021

\title{
Editorial
}

\section{The impact of COVID-19 quarantine on youth: from physical inactivity to pediatric depreobesity}

Impacto de la cuarentena por COVID-19 en jóvenes: de la inactividad física a la depreobesidad pediátrica

\author{
Chulvi-Medrano $\mathbf{I}^{1}$; Villa-González, $\mathbf{E}^{2}$; Rial-Rebullido, $\mathbf{T}^{3}$; Faigenbaum, $\mathbf{A D}^{4}$ \\ Corresponding author \\ Emilio Villa-González \\ PROFITH "PROmoting FITness and Health through physical activity" Research Group, Department of \\ Physical Education and Sports, Faculty of Education and Sport Sciences, Sport and Health University \\ Research Institute (iMUDS), University of Granada, Melilla 52071, Spain. \\ evilla@ugr.es
}

\section{Key Points}

- Scarce literature has described the impact of COVID-19 on youth levels of moderate to vigorous physical activity.

- Physical inactivity and social distancing could lead to physical and psychosocial problems increasing the risk of obesity and depression.

- Regular moderate to vigorous physical activity plays an essential role to limit or prevent the negative consequences of prolonged quarantine periods on pediatric depreobesity.

While nationwide quarantine has proven to be effective in containing the coronavirus disease (COVID-19) spread, the far-reaching detrimental effects of restrictive stay at home measures on youth between 6-18 years of age are yet to be known. The coronavirus pandemic has impacted youth's physical activity levels and opportunities for outdoor play, physical education classes and participation in sports. Recent studies have highlighted the health risks of prolonged lock-downs across adult populations ${ }^{1,2}$. However, scarce literature has described the impact of COVID-19 on levels of moderate to vigorous physical activity (MVPA) in children and adolescents.

Disturbingly only 2 in 10 youth worldwide accumulate the recommended 60 min of MVPA daily ${ }^{3}$. COVID-19 lockdown may have worsened the levels of youth physical inactivity and the consequent associated comorbidities. The multi-faceted consequences of abruptly increasing physical inactivity, sedentary behaviours, and overeating due to quarantine will start to emerge. Social distancing could lead to frustration, social isolation, physiological disturbances, and other mental health concerns correlated with an increased risk of depression ${ }^{4}$. The combined effects of a stressful environment and a physically inactive lifestyle in youth act as a feedback loop that increases adverse lifestyle behaviors (e.g., poor sleep hygiene, increased screen time, and high energy food intake) that drive troubling health outcomes. This malignant combination of physical and psychosocial behaviors could lead to unhealthy weight gain and mental health deterioration, which has been coined as "depreobesity". Youth are not immune to this vicious cycle. The prognosis of COVID-19 on the psychosocial health status as well as physical wellbeing in youth can no longer be ignored ${ }^{6}$. Figure 1 illustrates the depreobesity feedback loop consequent to homestay on youth. 


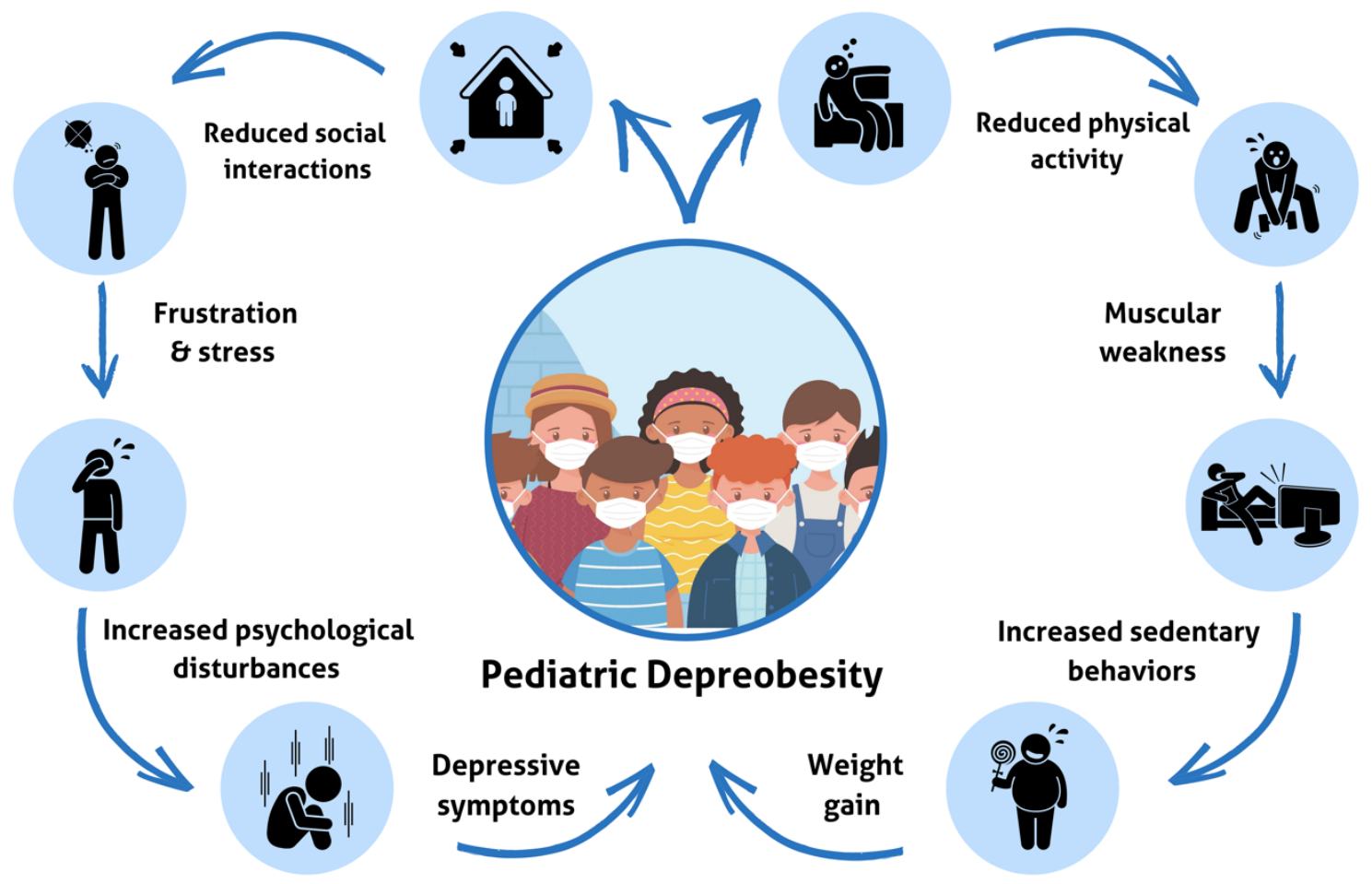

Figure 1. The pediatric depreobesity loop.

In order to limit or prevent the negative consequences of prolonged quarantine periods on pediatric depreobesity, regular MVPA plays an essential role. MVPA can be an enjoyable and cost-free strategy to prevent pediatric depreobesity during periods of confinement caused by COVID-19. However, if the current situation continues to worsen and more lockdown periods occur, the current global recommendations for youth physical activity (i.e., $\geq 60$ minutes of MVPA daily) should be reviewed and updated, due to the substantial increase in their physical inactivity. Of note, higher levels of muscular fitness lead to improvements in motor confidence and competence, which could further contribute to increased motivation to participate in $\mathrm{MVPA}^{7}$. Accumulating evidence highlights the importance of integrating both health and skill-related components of physical fitness to improve the physical and psychological wellbeing of youth ${ }^{4,8}$. In the specific case of obese youth, integrative interventions that improve strength and power could act as a primary positive driver in the depreobesity feedback loop, preserving the health of the young 9 . Since the performance of neuromuscular tasks has shown to be better in obese children than in their non-obese counterpartners, this could lead to positive experiences and improved performance, thereby increasing adherence to $\mathrm{MVPA}^{4,7}$. The global recommendations for youth resistance training have been established (e.g., 2-3 days/week; 20-30 minutes including a variety of exercises performed throughout the full range of motion without undue fatigue. It is reasonable to begin resistance training with $1-2$ sets of 8 to 12 repetitions using a low intensity $(\leq 60 \%$ of one repetition maximun) as proper technique is developed. More details about youth resistance training regimens and benefits can be found in a recent clinical report ${ }^{10}$.

Youth are a vulnerable population at risk for the negative effects of the COVID-19 quarantine whereby physical inactivity, low muscle strength, obesity, social isolation and poor mental health status 
could lead to pediatric depreobesity. We promote concerted efforts to encourage all girls and boys to regular participation in MVPA, including strength-building activities during the quarantine to prevent the health consequences of pediatric depreobesity ${ }^{10}$. Healthy lifestyle interventions designed to activate inactive youth, as well as international awareness of the complex interactions between physical activity and mental health among youth, are urgently warranted. We present the concept of pediatric depreobesity to open the scientific debate and welcome future research on this novel construct.

\section{References}

1. Jiménez-Pavón D, Carbonell-Baeza A, Lavie CJ. Physical exercise as therapy to fight against the mental and physical consequences of COVID-19 quarantine: Special focus in older people. Progress in Cardiovascular Diseases. 2020 (In press). DOI: 10.1016/j.pcad.2020.03.009

2. Lippi G, Henry BM, Bovo C, Sanchis-Gomar F. Health risks and potential remedies during prolonged lockdowns for coronavirus disease 2019 (COVID-19). Diagnosis. 2020;7(2):85-90. DOI: $10.1515 / \mathrm{dx}-2020-0041$

3. Aubert S, Barnes JD, Abdeta C, Nader PA, Adeniyi AF, Aguilar-Farias N, et al. Global Matrix 3.0 physical activity Report Card grades for children and youth: Results and analysis from 49 countries. Journal of Physical Activity and Health. 2018;15(S2):S251-73. DOI: 10.1123/jpah.2018-0472

4. Ten Hoor GA, Plasqui G, Ruiter RAC, Kremers SPJ, Rutten GM, Schols AMWJ, et al. A new direction in psychology and health: Resistance exercise training for obese children and adolescents. Psychology and Health. 2016;31:1-8. DOI: 10.1080/08870446.2015.1070158

5. Mediouni M, Kaczor-Urbanowicz KE, Madiouni R. Future epidemic: Depreobesity. Obesity Medicine. 2020;19:100240. DOI: 10.1016/j.obmed.2020.100240

6. Liu JJ, Bao Y, Huang X, Shi J, Lu L. Mental health considerations for children quarantined because of COVID-19.The Lancet Child and Adolescent Health. 2020;4:347-9. DOI: 10.1016/S23524642(20)30096-1

7. Faigenbaum AD, MacDonald JP, Carvalho C, Rebullido TR. The pediatric inactivity triad: A triple jeopardy for modern day youth. ACSM's Health \& Fitness Journal. 2020;24(4):10-7. DOI: 10.1249/FIT.0000000000000584

8. Myer GD, Faigenbaum AD, Edwards NM, Clark JF, Best TM, Sallis RE. Sixty minutes of what? A developing brain perspective for activating children with an integrative exercise approach. British Journal of Sports Medicine. 2015;49(23):1510-6. DOI: 10.1136/bjsports-2014-093661

9. Sigal RJ, Alberga AS, Goldfield GS, Prud'homme D, Hadjiyannakis S, Gougeon R, et al. Effects of aerobic training, resistance training, or both on percentage body fat and cardiometabolic risk markers in obese adolescents: The healthy eating aerobic and resistance training in youth randomized clinical trial. JAMA Pediatr. 2014;168(11):1006-14. DOI: 10.1001/jamapediatrics.2014.1392

10. Stricker PR, Faigenbaum AD, Mccambridge TM, Sports ON. Resistance training for children and adolescents. Pediatrics. 2020;145(6):e20201011. DOI: 10.1542/peds.2020-1011

\footnotetext{
Affiliations

${ }^{1}$ UIRFIDE (Sport Performance and Physical Fitness Research Group). Department of Physical and Sports Education. Faculty of Physical Activity and Sport Sciences. University of Valencia, Valencia, Spain.

${ }^{2}$ PROFITH "PROmoting FITness and Health through physical activity" Research Group, Department of Physical Education and Sports, Faculty of Education and Sport Sciences, Sport and Health University Research Institute (iMUDS), University of Granada, Melilla 52071, Spain.

${ }^{3}$ Tamara Rial Exercise \& Women's Health, Newtown, USA.
} 
DOI: https://doi.org/10.5027/jmh-Vol18-Issue1(2021)art100

${ }^{4}$ Department of Health and Exercise Science, The College of New Jersey, Ewing, NJ, USA.

\section{Authorship contributions}

ICH-M conceived the idea. ICH-M and EV-G wrote the manuscript. TR-R created the figure and TR-R and ADF made critical revisions. All authors read and approved the final version of the manuscript.

\section{Declaration of conflict of interest}

The authors declare no conflict of interest.

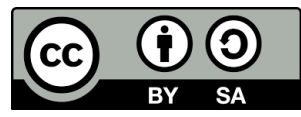

Copyright (c) 2021 Journal of Movement and Health. This document is published with the Open Access policy. Distributed under the terms and conditions of Creative Commons 4.0 International. https://creativecommons.org/licenses/by-sa/4.0/ 